This is the accepted manuscript of the article, which has been published in

Bmj supportive and palliative care. http://dx.doi.org/10.1136/bmjspcare-2019-001802

\title{
Has there been a change in the end-of-life decision-making over the past sixteen years?
}

Corresponding author: Reetta P. Piili, M.D. ${ }^{1,2}$

${ }^{1}$ Faculty of Medicine and Health Technology, Tampere University, Tampere, Finland

${ }^{2}$ Department of Oncology, Tampere University Hospital, Tampere, Finland

Address: Tampere University Hospital, Department of Oncology, Palliative Care Unit

Teiskontie 35, R-building, 33520 Tampere, FINLAND

Email: reetta.piili@tuni.fi

Tel. +358 331163161

Juho T. Lehto, M.D., Ph.D. ${ }^{1,2}$

${ }^{1}$ Faculty of Medicine and Health Technology, Tampere University, Tampere, Finland

${ }^{2}$ Department of Oncology, Tampere University Hospital, Tampere, Finland

Email: juho.lehto@tuni.fi

Metsänoja Riina, M.Sc. ${ }^{3}$

${ }^{3}$ Faculty of Social Sciences, Tampere University, Tampere, Finland

Email: riina.metsanoja@gmail.com

Heikki Hinkka, M.D., Ph.D. ${ }^{4}$

${ }^{4}$ Kangasala, Finland

Email: h.hinkka@kolumbus.fi

Pirkko-Liisa I. Kellokumpu-Lehtinen, M.D., Ph.D., Professor ${ }^{1,2}$

${ }^{1}$ Faculty of Medicine and Health Technology, Tampere University, Tampere, Finland

${ }^{2}$ Department of Oncology, Tampere University Hospital, Tampere, Finland

Email: pirkko-liisa.kellokumpu-lehtinen@tuni.fi 
Word count: 3490

Key Words: End-of-life, Clinical Ethics, Decision-making

\section{ABSTRACT}

Objectives: Physicians' decision-making in end-of-life care includes many medical, ethical and juridical aspects. We studied the changes of these decisions over time and factors influencing them.

Methods: A postal survey including two hypothetical patient scenarios were sent to 1258 Finnish physicians in 2015 and to 1182 in 1999. The attitudes, values and background factors of the physicians were also enquired.

Results: The response rate was $56 \%$. The physicians' decisions to choose palliative approaches over active or intensive care increased from 1999 to 2015 when a terminally ill prostate cancer patient had probable iatrogenic GI-bleeding ( $53 \%$ vs $59 \%, p=0.014)$ and waited to meet his son ( $46 \%$ vs $60 \%, p<0.001)$ or a minister ( 53 vs $71 \%, \mathrm{p}<0.001)$. Training in end-of-life care independently increased palliative approaches. Patient's benefit ( $96 \%$ vs $99 \%, p=0.001)$, ethical values ( $83 \%$ vs $93 \%, p<0.001$ ) and patient's ( 68 vs $86 \%$, $p<0.001$ ) or physician's ( $44 \%$ vs $63 \%, p<0.001$ ) legal protection were considered more influential to the decisions in 2015, while the family's benefit was regarded as less influential to the decisions than it was in 1999 (37\% vs 25\%, p<0.001). Physicians were more willing to give a hospice voucher for an advanced breast cancer patient in 2015 (34\% vs 58\%, p<0.001).

Conclusions: Our findings may reflect the transition to a stronger emphasis on patient-centred care and a stronger tendency to avoid futile therapies that have only short-term goals.

The results highlight that education in all aspects of end-of-life care should be incorporated into the postgraduate training of medical specialties that take care of dying patients. 


\section{INTRODUCTION}

Individualism has been rising in western countries.[1,2] This can also be seen in medicine, where shared decision-making and patient-centred care are now preferred by most physicians and patients.[3-5] However, concerns have been raised about the excessive autonomy of patients, which can result in costly, ineffective and even futile treatments.[6] The right of the patient to be involved in treatment decisions was included in Finnish law in 1992.[7] However, the Finnish National Supervisory Authority for Welfare and Health has stated that ineffective or futile therapies should not be used even though the patient requests them.[8] Physicians have to strike a balance between the wishes of the patient and family, legal and ethical aspects and evaluate the benefit, harm and cost of the care. This makes decision-making very challenging.

Decision-making in end-of-life (EOL) care involves many ethical, legal, medical and psychological aspects, and physicians' background characteristics, specialties, attitudes and values play a part in this complex process. [9-15] The specialty of a physician impacts their decision-making, as oncologists have been shown to be more opposed to accepting the risk of hastening death by using high doses of drugs for symptom control compared to other specialties, but they are more willing to withhold or withdraw futile treatments in EOL-care. $[12,16,17]$ Religion is shown to be associated with the unwillingness to withdraw lifesupportive care, $[16,18,19]$ whereas age and gender of the physician are inconsistent factors in the decision-making.[11, 17, 19-21]

Decision-making should be consistent in the same types of clinical situations regardless of the physician who is responsible for the care of the patient. The surrounding society and atmosphere do change over time, which might also influence the medical decisions. As the values and attitudes of the physician have a great impact on the decision-making, it is important to know whether these have changed over the years and how the possible changes affect the decisions that physicians make regarding EOL-care. A better understanding of the background factors and changes in decision-making will help to define important educational aspects of decision-making in EOL-care and will help to produce practical guidelines to provide 
high-quality and equal care to all patients.

The aim of this study was to identify whether, physicians' decision-making has changed over the past sixteen years and to explore the factors influencing and explaining these decisions.

\section{METHODS}

\section{Participants}

A postal survey with a similar questionnaire was conducted in 1999 and 2015 with Finnish physicians. In both years, the sample included 500 general practitioners (GPs), 300 surgeons, and 300 internists who were randomly selected from the register of the Finnish Medical Association, together with all Finnish oncologists ( $n=82$ in 1999 and $n=158$ in 2015). Non-responders were reminded twice. A cover letter including an introduction to the study, an assurance of anonymity and a statement of voluntariness was mailed together with the questionnaire. This study was approved by the Regional Ethics Committee of Tampere University Hospital, Finland (R15101).

\section{Questionnaire}

Seven hypothetical patient scenarios were presented in the questionnaire. Following the patient scenarios, attitudes regarding several moral and ethical aspects were assessed with a 100-mm visual analogue scale (VAS) from "definitely agree" $(0 \mathrm{~mm})$ to "definitely disagree" (100 mm). These included, for example, statements concerning euthanasia, palliative care, the role of religion in ethical decisions, advanced directives and health care economics, together with physicians' satisfaction with their own health, work and salary. There were also questions concerning the responders' background and personal features. Changes in these attitudes have been reported earlier.[22] The questionnaire has been previously used and validated with Finnish physicians.[10, 11] 


\section{Patient scenarios}

We included two patient scenarios in this study:

Scenario 1 presented an 82-year-old retired forest worker, who had received a diagnosis of prostatic cancer 3 years ago. During the past year he received treatments for bone metastases. He has now been in hospital for one month, almost totally bedridden, and needs help with all functions. His mental condition has been normal. His general condition has weakened over the past week, he is now totally bedridden, and he has received large doses of pain medication. Today, he has become comatose. His haemoglobin count has decreased to $68 \mathrm{~g} / \mathrm{l}$, while the week before it was $118 \mathrm{~g} / \mathrm{l}$. His blood pressure is $80 / 40 \mathrm{mmHg}$. There is no verbal or written advance directive. The patient's wife has previously said that she expects the doctor to make all treatment decisions according to his/her best understanding. After the scenario, the doctors were asked to choose one of the given treatment options. The concepts used in the treatment options were explained as follows: 1) palliative care: good nursing, sufficient medications for pain and other symptoms, intravenous hydration only when it is considered to relieve the patient's symptoms; 2) active care: use of antibiotics, intravenous hydration or blood transfusions aimed at saving the patient's life in a lifethreatening condition; 3) intensive care: moving the patient to an intensive care unit (ICU). After the initial question for scenario 1 , four additional alternatives were presented, each ending with the same treatment options: a) It has been discovered that the patient's faeces are black. You remember having prescribed ketoprophen for pain a week ago; b) The patient's son is coming from America the day after tomorrow to see his father while he is still alive; c) The patient has had spiritual anxiety and there is a planned appointment with a minister and the Lord's Supper tomorrow; d) The patient's written advance directive has been found, in which the patient has expressed that all active interventions should be withheld if there is no hope for recovery. After asking for the treatment decisions, a Likert-type scale was presented to evaluate the influence of different factors (patient's benefit, family's benefit, patient's legal protection, physician's legal protection, ethical values, patient's age, cost of care, patient's social status) on the 
decisions (from 1-very little influence to 5-very much influence).

In scenario 2, a 68-year-old patient suffers from breast cancer with bone metastases. She is bedridden and her general condition has rapidly collapsed. She is in a community hospital ward and is receiving adequate pain treatment with which she is pleased. She is depressed and wants to transfer to a hospice for her last days. She feels that the atmosphere on the ward is very restless and "institutional". You have the right to issue a voucher for the costs of hospice care (290 euros per day) to be paid by the community hospital. The costs would be approximately double compared to those in a community hospital, and the chief doctor has advised you to use great discretion in issuing vouchers. Your solution: a) to accept the transfer b) to accept the transfer, provided that the patient pays the extra costs herself c) not to accept, because according to normal practice the patient's care belongs to the community hospital ward, and there are no special problems in her care d) I don't know e) other solution.

Responders were instructed at the outset to answer the questions in sequence from beginning to the end and not to change their answers later.

\section{Statistical analysis}

In the patient scenarios, the answers were converted into two options. In patient scenario 1: choosing palliative care (response a) or choosing active and intensive care (responses $b$ and $c$ ). In patient scenario 2: willing to give a voucher for hospice (response a) or not willing to give a voucher (other responses). The answers on the 4-point Likert scale concerning values were converted to the following 2-point scale: 1-2 for "not important" and 3-4 for "important", and the answers on the 5-point Likert scale concerning the influence of different factors were converted to the following 2-point scale: 1-3 for "not much influence" and 4-5 for "much influence".

The two-scale patient scenarios, background factors and values were tested using the Pearson chi-square 
test. Two-sided $p$-vales that were less than 0.05 were considered to be statistically significant.

The models explaining the decision to choose palliative care in patient scenario 1 and willingness to give a voucher for hospice in patient scenario 2 were created using forward stepwise logistic regression. Models were created from the scenarios that had a statistically significant difference between the study years. Background factors, life values, and attitudes were all included in the model.[22] The p-value for significance was set at 0.10 to enter and 0.15 to remove from the model.

The data analysis was performed using IBM SPSS Statistics for Windows, Version 23.0 (Armonk, NY: IBM Corp. Released 2014).

\section{RESULTS}

\section{Responders}

The characteristics of the responders are presented in Table 1. Altogether 1373 valid responses were obtained. In 1999, the responders were younger $(p<0.001)$, had shorter working experience $(p<0.001)$ and were more often men $(p<0.001)$ compared to the responders in 2015 . Oncologists reported having participated in post-graduate end-of-life training significantly more often $(p<0.001)$ than other physicians (58\% vs $22 \%)$. 
Table 1. Characteristics of the participants.

\begin{tabular}{|c|c|c|c|c|c|c|c|c|c|c|c|c|c|c|c|c|c|c|c|c|}
\hline & \multicolumn{4}{|c|}{ Surgeons } & \multicolumn{4}{|c|}{ Internists } & \multicolumn{4}{|c|}{ GPs } & \multicolumn{4}{|c|}{ Oncologists } & \multicolumn{4}{|c|}{ Total } \\
\hline & & 1999 & & 2015 & & 1999 & & 2015 & & 1999 & & 2015 & & 1999 & & 2015 & & 1999 & & 2015 \\
\hline Number (\% of total) & 175 & (24) & 142 & (22) & 184 & (25) & 153 & (24) & 316 & (43) & 245 & (38) & 54 & (7) & 104 & (16) & 729 & (100) & 644 & (100) \\
\hline Response rate, \% & & 58 & & 47 & & 61 & & 47 & & 63 & & 49 & & 51 & & 66 & & 62 & & 51 \\
\hline Female, n (\%) & 33 & (19) & 47 & (33) & 60 & (33) & 81 & (53) & 170 & (55) & 173 & (71) & 30 & (56) & 85 & (82) & 293 & (41) & 386 & (60) \\
\hline Mean age (range) & 48 & $(33-66)$ & 51 & $(33-64)$ & 48 & $(32-70)$ & 52 & $(33-65)$ & 42 & $(25-63)$ & 47 & $(25-65)$ & 46 & $(35-61)$ & 48 & $(32-67)$ & 45 & $(25-70)$ & 50 & $(25-67)$ \\
\hline \multicolumn{21}{|l|}{ Working place* } \\
\hline Outpatient unit & 1 & (1) & 2 & (1) & 15 & (9) & 15 & (10) & 242 & (78) & 208 & (86) & 2 & (4) & 4 & (4) & 260 & (37) & 229 & (36) \\
\hline Hospital & 146 & (85) & 124 & (88) & 123 & (71) & 122 & (82) & 33 & (11) & 24 & (10) & 44 & (83) & 91 & (88) & 346 & (49) & 361 & (57) \\
\hline Other & 24 & (14) & 15 & (11) & 35 & (20) & 12 & (8) & 35 & (11) & 10 & (4) & 7 & (13) & 8 & (8) & 101 & (14) & 45 & (7) \\
\hline $\begin{array}{l}\text { Years from } \\
\text { graduation, median } \\
\text { (range) }^{* *}\end{array}$ & 22 & $(2-42)$ & 26 & $(7-42)$ & 21 & $(7-41)$ & 26 & $(8-42)$ & 16 & $(1-35)$ & 21 & $(0-40)$ & 18 & $(9-34)$ & 22 & $(7-40)$ & 19 & $(1-42)$ & 23 & $(0-42)$ \\
\hline Married, n (\%) & 140 & (81) & 119 & (84) & 142 & (79) & 124 & (81) & 228 & (73) & 198 & (81) & 45 & (83) & 71 & (71) & 555 & (77) & 512 & (80) \\
\hline
\end{tabular}

* For 32 participants working place was not available

**For 19 participants year of graduation was not available

GP, general practitioner 


\section{Change in decision-making}

The overall changes in decision-making in the different patient scenarios according to physician group are shown in Table 2. Statistically significant changes towards the palliative care approach were found when the terminally ill prostate cancer patient had probable iatrogenic Gl-bleeding (scenario 1a), his son was coming to see him in two days (scenario $1 \mathrm{~b}$ ) and he had a Lord's Supper with a minister planned for the next day (scenario 1c). The oncologists' approach remained unchanged during the years studied. When an advance directive was found, most physicians ( $86 \%$ to $94 \%$ ) consistently chose a palliative care approach in both of the years studied. All of the physicians' groups were more willing to give a voucher for hospice to the patient with advanced breast cancer in 2015 than in 1999. 
Table 2. Numbers and proportions of physicians choosing a palliative care approach over active/intensive care for the terminally ill patient with a prostate cancer (scenario 1) and willing to give a voucher for hospice for the advanced breast cancer patient (scenario 2).

\begin{tabular}{|c|c|c|c|c|c|c|c|c|c|c|c|c|c|c|c|c|c|c|c|c|c|c|c|c|c|}
\hline \multirow{2}{*}{ Number (\%) } & \multicolumn{5}{|c|}{ Surgeons } & \multicolumn{5}{|c|}{ Internists } & \multicolumn{5}{|c|}{ GPS } & \multicolumn{5}{|c|}{ Oncologists } & \multicolumn{5}{|c|}{ Total } \\
\hline & \multicolumn{2}{|c|}{1999} & \multicolumn{2}{|c|}{2015} & $\begin{array}{c}p \\
\text {-value* }\end{array}$ & \multicolumn{2}{|c|}{1999} & \multicolumn{2}{|c|}{2015} & $\begin{array}{c}p- \\
\text { value* }\end{array}$ & \multicolumn{2}{|c|}{1999} & \multicolumn{2}{|c|}{2015} & $\begin{array}{c}p- \\
\text { value* }\end{array}$ & \multicolumn{2}{|c|}{1999} & \multicolumn{2}{|c|}{2015} & $\begin{array}{c}p- \\
\text { value* }\end{array}$ & \multicolumn{2}{|c|}{1999} & \multicolumn{2}{|c|}{2015} & $\begin{array}{c}p- \\
\text { value* }\end{array}$ \\
\hline Scenario 1 & 145 & (84) & 118 & (84) & 0.381 & 145 & (80) & 124 & (82) & 0.642 & 263 & (84) & 198 & $(82)$ & 0.712 & 48 & (89) & 87 & (84) & 0.376 & 601 & (83) & 527 & (83) & 0.712 \\
\hline Scenario 1a & 97 & (56) & 76 & (55) & 0.860 & 86 & (47) & 86 & (57) & 0.067 & 160 & (51) & 145 & $(60)$ & 0.024 & 38 & $(70)$ & 67 & (64) & 0.453 & 381 & (53) & 374 & (59) & 0.014 \\
\hline Scenario 1b & 81 & (47) & 84 & (61) & 0.015 & 78 & (43) & 87 & (57) & 0.010 & 139 & (44) & 145 & $(60)$ & $<0.001$ & 31 & (57) & 64 & (62) & 0.565 & 330 & (46) & 380 & $(60)$ & $<0.001$ \\
\hline Scenario 1c & 91 & (52) & 95 & (67) & 0.007 & 97 & (53) & 105 & (69) & 0.003 & 161 & (51) & 171 & (71) & $<0.001$ & 34 & (64) & 79 & (76) & 0.119 & 384 & (53) & 450 & (71) & $<0.001$ \\
\hline Scenario 1d & 149 & (86) & 127 & (90) & 0.234 & 156 & (86) & 134 & (89) & 0.486 & 291 & (92) & 227 & (93) & 0.674 & 48 & (89) & 98 & (94) & 0.229 & 644 & (89) & 586 & (92) & 0.078 \\
\hline Scenario 2 & 61 & (35) & 89 & (63) & $<0.001$ & 61 & (33) & 102 & (67) & $<0.001$ & 99 & (31) & 121 & (50) & $<0.001$ & 23 & (43) & 59 & (57) & 0.092 & 244 & (34) & 371 & (58) & $<0.001$ \\
\hline
\end{tabular}

* Pearson Chi-square test

Scenario 1: Prostate cancer patient (original scenario)

Scenario 1a: Prostate cancer patient with black feaces after ketoprophen prescription

Scenario 1b: Prostate cancer patient waiting to meet his son the day after tomorrow

Scenario 1c: Prostate cancer patient waiting to meet a minister tomorrow

Scenario 1d: Prostate cancer patient with the advance directive

Scenario 2: Breast cancer patient 


\section{Physicians' opinions on the factors influencing their decisions}

Physicians' opinions on the factors influencing their decisions concerning the terminally ill prostate cancer patient are summarized in Table 3. Patient's benefit, ethical values and patient's or physician's legal protection were more influential on the physicians' decision-making in 2015 , while influence of family's benefit and patient's age decreased.

Table 3. Factors reported by the physicians to have influenced to their decisions concerning the care of the terminally ill prostate cancer patient.

$19992015 \quad p$-value*

Having much influence

\begin{tabular}{|c|c|c|c|c|c|}
\hline Patient's benefit & 700 & $(96 \%)$ & 628 & (99\%) & 0.001 \\
\hline Family's benefit & 265 & $(37 \%)$ & 166 & $(25 \%)$ & $<0.001$ \\
\hline Patient's legal protection & 493 & $(68 \%)$ & 545 & $(86 \%)$ & $<0.001$ \\
\hline Physician's legal protection & 319 & $(44 \%)$ & 401 & $(63 \%)$ & $<0.001$ \\
\hline Ethical values & 599 & $(83 \%)$ & 638 & (93\%) & $<0.001$ \\
\hline Patient's age & 335 & $(46 \%)$ & 255 & $(40 \%)$ & 0.023 \\
\hline Costs of care & 68 & (9\%) & 61 & $(10 \%)$ & 0.861 \\
\hline Patient's social status & 13 & $(2 \%)$ & 5 & (1\%) & 0.106 \\
\hline
\end{tabular}

* Pearson Chi-square test 


\section{Factors associated with physicians' decisions}

The results from the logistic regression analysis of the decisions concerning the terminally ill prostate cancer patient with probable iatrogenic GI-bleeding and who was waiting to meet his son or a minister (scenarios 1a-c) are presented in Table 4. The year of the survey remained a significant independent factor explaining the physicians' decision in every scenario. In general, the physicians answering in 2015 were less eager to choose active or intensive care. The willingness to withdraw life-sustaining treatments and having post-graduate EOL training were also significantly associated with a decreased likelihood of choosing active and intensive care in these scenarios. In addition, men more often chose a palliative care approach for the terminally ill prostate cancer patient when Gl-bleeding was detected and when his son was coming. 
Table 4. Different background factors and attitudes explaining the decision to choose active/intensive care ( $n=482)$ over a palliative care approach $(n=610)$ concerning the prostate cancer patient with probably iatrogenic GI-bleeding and when he is waiting to meet his son or a minister (scenarios 1a-c) in forward logistic regression analysis.

\begin{tabular}{|c|c|c|c|c|c|c|c|c|c|c|c|c|}
\hline & & & Scenario 1a & & & & scenario $1 b$ & & & & Scenario 1c & \\
\hline & $\mathrm{n}$ & OR & $(95 \% \mathrm{Cl})$ & $p$-value & $\mathrm{n}$ & OR & $(95 \% \mathrm{Cl})$ & $p$-value & $\mathrm{n}$ & OR & $(95 \% \mathrm{Cl})$ & $\mathrm{p}$-value \\
\hline Year of the survey & & & & 0.006 & & & & $<0.001$ & & & & $<0.001$ \\
\hline 1999 & 578 & ref. & & & 579 & ref. & & & 580 & ref. & & \\
\hline 2015 & 514 & 0.65 & $(0.48,0.88)$ & & 515 & 0.41 & $(0.30,0.56)$ & & 515 & 0.47 & $(0.36,0.63)$ & \\
\hline $\begin{array}{l}\text { Withdrawal of life-sustaining } \\
\text { treatments is reprehensible }\left(\mathrm{VAS}^{\mathrm{a}}\right)\end{array}$ & 1092 & 0.92 & $(0.87,0.97)$ & 0.001 & 1094 & 0.94 & $(0.90,0.99)$ & 0.028 & 1095 & 0.91 & $(0.86,0.96)$ & 0.001 \\
\hline $\begin{array}{l}\text { People should pay costs of factitious } \\
\text { diseases by themselves }\left(\text { VAS }^{a}\right)\end{array}$ & 1092 & 0.96 & $(0.91,1.00)$ & 0.071 & & & & & & & & \\
\hline $\begin{array}{l}\text { Advance directives have been } \\
\text { helpful in my decisions }\left(\text { VAS }^{a}\right)\end{array}$ & & & & & 1094 & 0.95 & $(0.90,0.99)$ & 0.028 & 1095 & 0.95 & $(0.90,0.99)$ & 0.029 \\
\hline I'm pleased with my salary $\left(V^{\prime} S^{a}\right)$ & & & & & 1094 & 0.96 & $(0.92,1.00)$ & 0.049 & & & & \\
\hline $\begin{array}{l}\text { Religion has influence when I make } \\
\text { ethical decisions (VAS') }\end{array}$ & & & & & & & & & 1095 & 0.93 & $(0.89,0.97)$ & $<0.001$ \\
\hline $\begin{array}{l}\text { It is waste of resources to treat } \\
\text { patients over } 80 \text { years of age in } \\
\text { intensive care units (VAS })\end{array}$ & 1092 & 1.07 & $(1.02,1.13)$ & 0.009 & & & & & 1095 & 1.05 & $(1.00,1.11)$ & 0.065 \\
\hline Gender & & & & 0.005 & & & & 0.001 & & & & \\
\hline Female & 537 & ref. & & & 539 & ref. & & & & & & \\
\hline Male & 555 & 0.67 & $(0.51,0.88)$ & & 555 & 0.65 & $(0.50,0.84)$ & & & & & \\
\hline $\begin{array}{l}\text { Marital status } \\
\text { Single }\end{array}$ & & & & & & & & & 68 & ref. & & 0.055 \\
\hline
\end{tabular}


Common-law marriage

\section{Married}

\section{Divorced}

Widowed

Time from graduation (years)

Amount of administrative work (hours)

Taking care of a family member in end-of-life

No

Yes

Post-graduate end-of-life training

$$
\text { No }
$$

Yes

Length of Life

$$
\text { Important }
$$

\begin{tabular}{|c|c|c|c|c|c|c|c|c|c|c|c|}
\hline & & & & & & & & 98 & 0.82 & $(0.43,1.57)$ & 0.554 \\
\hline & & & & & & & & 841 & 0.63 & $(0.37,1.06)$ & 0.080 \\
\hline & & & & & & & & 76 & 1.16 & $(0.58,2.32)$ & 0.667 \\
\hline & & & & & & & & 12 & 0.92 & $(0.26,3.31)$ & 0.899 \\
\hline 1092 & 0.99 & $(0.97,1.00)$ & 0.058 & & & & & 1095 & 0.99 & $(0.97,1.00)$ & 0.047 \\
\hline 1092 & 0.98 & $(0.97,1.00)$ & 0.055 & 1094 & 0.98 & $(0.97,1.00)$ & 0.024 & & & & \\
\hline & & & 0.006 & & & & & & & & \\
\hline 422 & ref. & & & & & & & & & & \\
\hline 670 & 0.69 & $(0.52,0.90)$ & & & & & & & & & \\
\hline & & & $<0.001$ & & & & $<0.001$ & & & & 0.011 \\
\hline 808 & ref. & & & 809 & ref. & & & 810 & ref. & & \\
\hline 284 & 0.54 & $(0.39,0.73)$ & & 285 & 0.60 & $(0.45,0.80)$ & & 285 & 0.68 & $(0.51,0.92)$ & \\
\hline & & & 0.089 & & & & & & & & \\
\hline 799 & ref. & & & & & & & & & & \\
\hline 293 & 0.77 & $(0.57,1.04)$ & & & & & & & & & \\
\hline & & & 0.093 & & & & & & & & \\
\hline 121 & ref. & & & & & & & & & & \\
\hline 251 & 1.44 & $(0.85,2.42)$ & 0.173 & & & & & & & & \\
\hline 270 & 1.84 & $(1.11,3.04)$ & 0.018 & & & & & & & & \\
\hline 450 & 1.35 & $(0.85,2.13)$ & 0.206 & & & & & & & & \\
\hline
\end{tabular}

Not important

aAS, visual analogue scale (0 definitely agree, 10 definitely disagree). One unit is equivalent to $10 \mathrm{~mm}$ on a $100-\mathrm{mm}$ VAS

GP, General Practitioner

ref., reference 
Table 5 shows the results from the logistic regression analysis for the factors associated with the willingness to give a hospice voucher to the breast cancer patient with advanced disease (scenario 2 ). In the analysis, the responders in 2015 were more willing to give a voucher than the responders in 1999.

Table 5. Different background factors and attitudes explaining the willingness to give a voucher for hospice $(n=488)$ versus not $(n=610)$ for the patient with advanced breast cancer (scenario 2) in forward logistic regression analysis.

\begin{tabular}{|c|c|c|c|c|}
\hline & $\mathrm{n}$ & OR & $(95 \% \mathrm{Cl})$ & $p$-value \\
\hline Year of the survey & & & & $<0.001$ \\
\hline 1999 & 582 & ref. & & \\
\hline 2015 & 516 & 2.62 & $(1.96,3.50)$ & \\
\hline $\begin{array}{l}\text { Withdrawal of life-sustaining } \\
\text { treatments is reprehensible } \\
\left(\text { VAS }^{a}\right)\end{array}$ & 1098 & 1.06 & $(1.00,1.12)$ & 0.051 \\
\hline $\begin{array}{l}\text { People should pay costs of } \\
\text { factitious diseases by } \\
\text { themselves }\left(\mathrm{VAS}^{\mathrm{a}}\right)\end{array}$ & 1098 & 1.07 & $(1.02,1.13)$ & 0.004 \\
\hline $\begin{array}{l}\text { Physicians can't estimate } \\
\text { cancer pain }\left(V^{\prime} S^{a}\right)\end{array}$ & 1098 & 0.93 & $(0.89,0.98)$ & 0.006 \\
\hline My health is excellent (VAS ${ }^{a}$ ) & 1098 & 1.10 & $(1.04,1.18)$ & 0.003 \\
\hline $\begin{array}{l}\text { It is waste of resources to treat } \\
\text { patients over } 80 \text { years of age in } \\
\text { intensive care units }\left(\mathrm{VAS}^{\mathrm{a}}\right)\end{array}$ & 1098 & 1.07 & $(1.01,1.12)$ & 0.017 \\
\hline Gender & & & & 0.084 \\
\hline Female & 541 & ref. & & \\
\hline Male & 557 & 0.78 & $(0.59,1.03)$ & \\
\hline Age (years) & 1098 & 0.98 & $(0.96,0.99)$ & 0.003 \\
\hline $\begin{array}{l}\text { Post-graduate end-of-life } \\
\text { training }\end{array}$ & & & & 0.089 \\
\hline No & 811 & ref. & & \\
\hline Yes & 287 & 0.76 & $(0.56,1.04)$ & \\
\hline Physician groups & & & & 0.007 \\
\hline Oncologists & 121 & ref. & & \\
\hline Surgeons & 254 & 0.92 & $(0.55,1.54)$ & 0.760 \\
\hline Internists & 271 & 0.93 & $(0.57,1.52)$ & 0.761 \\
\hline
\end{tabular}


$\bar{a}$ VAS, visual analogue scale (0 definitely agree, 10 definitely disagree). One unit is equivalent to $10 \mathrm{~mm}$ on a 100-mm VAS.

GP, General Practitioner

ref., reference

\section{DISCUSSION}

Physicians in 2015 chose a palliative care approach more often than those in 1999 for the terminally ill prostate cancer patient when he had probable iatrogenic Gl-bleeding and when he was waiting to meet his son or a minister in the next few days. The physicians thought that their decision-making was more influenced by patient's benefit, ethical values and patient's or physician's legal protection and less by family's benefit and patient's age than did the physicians in 1999 . They were also more willing to give a voucher for hospice when the patient with advanced breast cancer wished for it during her EOL-care.

Palliative care as defined by the World Health Organization (WHO) aims to improve the quality of life of patients and their families when facing life-threatening illness, it neither hastens nor postpones death.[23] In our study, most of the physicians chose a palliative care approach for the prostate cancer patient in the EOL-care situation when no additional ethical complexities were present. This basic decision-making did not change between the years studied, showing the general medical acceptability of palliative care in this hypothetical case scenario. Further, after finding the patient's advance directive stating that active treatments should be withheld if there is no hope for recovery, almost all physicians chose a palliative care approach, without difference between the years examined. This is well in line with earlier studies showing that advance directives help decision-making in EOL-care, although physicians are concerned whether advance directives genuinely express a patient's own will.[24, 25]

When two short-term goals (meeting the son or a minister in the next few days) and a suspicion of 
iatrogenic bleeding were presented, the proportion of the physicians choosing a palliative care approach decreased, but significantly less in 2015 than in 1999. These scenarios forced the responding physicians to make ethically demanding decisions. One can argue that life-sustaining interventions might be ethically justified as a part of the palliative care to achieve these patient-centred short-term goals. On the other hand, more aggressive life-prolonging interventions in this case scenario might lead to overwhelming and prolonged suffering, together with the substantial costs of futile treatments.

In 2015, physicians were less influenced by family's benefit, which probably reflects to their unwillingness to choose active and intensive care when the son of the terminally ill prostate cancer patient was coming. The lower influence of the family's benefit may be due to rising individualism in western countries.[1, 2] Religion has earlier been shown to have tremendous effect on end-of-life decisions.[16, 18, 19, 21, 26] We have previously shown that physicians had less faith in God and considered religion to be less influential in ethical decisions in 2015 than they did previously.[22] Thus, it is not surprising that an appointment with a minister shifted the treatment decisions to life-prolonging modalities less often in 2015 than in 1999. Guilt has been shown to be one of the reasons why futile treatments are carried on in EOL-care.[27] This could explain, at least to some extent, why approximately half of the physicians chose an active approach upon discovery of GI-bleeding that was likely caused by the previously prescribed ketoprophen, although this shift to life-sustaining treatment was slightly less common in 2015. Nevertheless, the principal justification for every treatment should be the patient's benefit, not the physician's attitudes and feelings in everyday decision-making. One of the reasons for the increased tendency to choose a palliative care approach in 2015 might be a better understanding of palliative care, which leads to the avoidance of futile therapies in EOL-care even in ethically complex situations. This assumption was further supported by the analysis of background factors for decision-making, which revealed an association between training in EOL-care and choosing a palliative care approach.

Using logistic regression analysis, we also investigated whether the changes between the years were genuine. It appeared that the significant differences in decision-making still remained after taking into 
account confounding factors. In addition, some other important factors that influenced to the decisions were discovered, including the constant effect of post-graduate end-of-life training. As a whole, physicians who considered the withdrawal of life-sustaining treatments to be less reprehensible chose a palliative care approach more often in all scenarios. This is understandable when taking into account the nature of palliative care, in which considering the withdrawal of life-sustaining treatments to be reprehensible could be problematic.

The age of the physician seems to be a conflicting factor in end-of-life decision-making.[19] In our previous study, younger age was associated with an unwillingness to withhold or withdraw therapies,[17] but in this study age did not explain the decisions to choose a palliative care approach. Male gender was associated with the palliative decision when the prostate cancer patient had probable GI-bleeding and when his son was coming the next day. The influence of gender is also unclear in end-of-life decisionmaking, as some studies have shown that female physicians are more in favour of active treatments and in some studies there is no gender-dependent difference in withholding or withdrawing life-sustaining treatments.[11, 17, 19, 20, 28]

Only approximately $10 \%$ of the respondents in both years considered costs of care to influence their decisions, and the patient's social status was even less influential. Some studies do report that a patient's financial resources influence physicians' decision-making,[29] while our results probably reflect the Finnish health care system, where the cost of care are covered by the society with tax money. The influence of a patient's age decreased during the years studied. This finding is likely due to the advances in medicine in recent years. In contrast to older studies where age significantly influenced patient survival in critical illnesses, $[30,31]$ the survival of cancer patients was not associated with age in a recent study by MartosBenítez el al.[32]

The influence of patient's benefit to physicians' decision-making rose to $99 \%$ from an already high percentage of $96 \%$, while family's benefit decreased from $37 \%$ to $25 \%$ between the years studied. The rise 
of individualism in western parts of the world might reflect this change, as well as the fact that today respecting the patient's wishes is one of the main principles in the ethical guidelines of the Finnish Medical Association. $[1,2,33]$ Both patient's and physician's legal protection was considered more influential now than sixteen years ago. In Finland, patient's rights regarding treatment decisions were incorporated into Finnish law in 1992,[7] which has obviously impacted the high level of influence of the patient's legal protection. Thus, our results also raise a question as to whether physicians are more concerned about malpractice claims now than they were sixteen years ago. The data from malpractice claims is conflicting, as some studies show an increasing amount of malpractice claims, while in others there is a clear decrease.[34, 35] In contrast to our results, the law appeared to play a limited role in end-of-life medical decision-making with doctors prioritizing patient-related clinical and ethical considerations in a recent study from Australia.[36] On the other hand, that study is partly in line with our study, as ethical values were also considered to be highly influential by our responders. Our findings emphasize the complexity of end-of-life decision-making and the different factors that affect it, as physicians consider both legal and ethical aspects to be important, and one does not exclude the other.

Physicians in 2015 were more willing to give a voucher for hospice, when the breast cancer patient in EOLcare wished for it. The increase in a palliative care approach for the terminally ill prostate cancer patient might reflect the tendency to avoid futile therapies even when contrasting with the patient's wishes. This increasing willingness to give a hospice voucher may in turn be a reflection of the rise in patient-centred care where there is a focus on shared decision-making complying with patient's preferences.[4, 5, 37] The difference between the study years remained in the logistic regression analysis concerning the patient with advanced breast cancer. However, GPs were more unwilling to give a voucher compared to oncologists. In Finland, most of the dying patients are taken care of in community hospitals by GPs. Thus, our finding may reflect the better knowledge of GPs about the facilities in the community hospitals or the financial realities in the communities. On the other hand, oncologists may face the most difficult cases in EOL-care, leading to a willingness to offer specialized palliative care in a hospice. Our results call for ongoing communication between the specialties to build up palliative care pathways with optimally arranged EOL-care based on the 
needs of every individual patient.

The limitations of this study need to be acknowledged. Our response rate $(56 \%)$ is a limitation, due to possible nonresponse bias even though our study population was a large and representable sample of Finnish physicians. Because the follow-up period is long, it was possible to detect relevant changes in attitudes, values and decision-making. Physicians responding questions regarding hypothetical scenarios might give different answers compered to their actual decisions in clinical practice, but we suggest that the answers do sufficiently reflect real-life decision-making. However, future research should try to evaluate the basis of decision-making in the clinical practise of EOL-care and whether education in palliative care influences these decisions.

\section{CONCLUSION}

Compared to 1999, physicians in 2015 were more reluctant to choose active life-prolonging treatments over palliative care approaches for short-term goals in EOL-care. However, they were more willing to give a voucher for hospice when a patient requested it. Patient's benefit, ethical values and patient's or physician's legal protection were more influential on the physicians' decision-making in 2015, while influence of family's benefit and patient's age decreased. Our findings may reflect changes in general attitudes and the medical atmosphere towards patient-centred care and the decreased importance of family and religion in Finnish society, together with a better knowledge of the principles of palliative care. The results highlight the importance of education of end-of-life care, including not only the medical facts but also the ethics related to decision-making. All of these aspects should be incorporated into postgraduate training in specialties that take care of dying patients.

\section{Acknowledgements}

Not applicable. 


\section{Authors' contributorship}

$\mathrm{RP}, \mathrm{JL}, \mathrm{HH}$ and PLKL designed the study outline and the questionnaire. RP, JL and PLKL collected the data.

$\mathrm{RP}, \mathrm{JL}, \mathrm{PLKL}$ and RM analysed the data. RP and RM performed the final statistical analysis. All the authors contributed to the writing and reviewing of the manuscript and approved the final manuscript.

\section{Competing Interests}

None declared.

\section{Data sharing}

The datasets used and analysed during the study are available from the corresponding author on a reasonable request.

\section{Ethics approval and consent to participate}

The study was approved by the Regional Ethics Committee of Tampere University Hospital, Finland (R15101) and participation was voluntary and anonymous.

\section{Funding}

This study was funded by the Seppo Nieminen Legacy Fund, the Signe and Ane Gyllenberg Foundation, the Finnish Medical Association and the Cancer Society of Pirkanmaa. The funders did not have any role in the design of the study; in the collection, analysis or interpretation of the data; or in the writing of the manuscript. 


\section{Licence for Publication}

I, Dr. Reetta Piili, the Submitting Author has the right to grant and does grant on behalf of all authors of the Work (as defined in the below author licence), an exclusive licence and/or a non-exclusive licence for contributions from authors who are: i) UK Crown employees; ii) where BMJ has agreed a CC-BY licence shall apply, and/or iii) in accordance with the terms applicable for US Federal Government officers or employees acting as part of their official duties; on a worldwide, perpetual, irrevocable, royalty-free basis to BMJ Publishing Group Ltd ("BMJ") its licensees and where the relevant Journal is co-owned by BMJ to the coowners of the Journal, to publish the Work in BMJ Supportive \& Palliative Care and any other BMJ products and to exploit all rights, as set out in our licence (http://group.bmj.com/products/journals/instructions-forauthors/licence-forms).

\section{References}

1. Greenfield PM. The changing psychology of culture from 1800 through 2000. Psychol Sci 2013, 24:17221731.

2. Twenge JM, Campbell WK, Gentile B. Increases in individualistic words and phrases in American books, 1960-2008. PLoS One 2012, 7:e40181.

3. Chewning B, Bylund CL, Shah B, et al. Patient preferences for shared decisions: a systematic review. Patient Educ Couns 2012, 86:9-18.

4. Murray E, Pollack L, White $M$, et al. Clinical decision-making: physicians' preferences and experiences. BMC Fam Pract 2007, 8:10-2296-8-10.

5. Belanger E, Rodriguez C, Groleau D. Shared decision-making in palliative care: a systematic mixed studies review using narrative synthesis. Palliat Med 2011, 25:242-261.

6. Graber MA, Tansey JF. Autonomy, consent, and limiting healthcare costs. J Med Ethics 2005, 31:424-426.

7. FINLEX. Laki potilaan asemasta ja oikeuksista. Potilaan itsemääräämisoikeus. 17.8.1992/785. https://www.finlex.fi/fi/laki/ajantasa/1992/19920785 (accessed 1 Oct 2018). 
8. The Finnish National Supervisory Authority for Welfare and Health. Patient's rights.

http://www.valvira.fi/web/en/healthcare/patient_rights (accessed 3 Oct 2018).

9. Daher M. Ethical issues in the geriatric patient with advanced cancer 'living to the end'. Ann Oncol 2013, 24:55-58.

10. Hinkka $\mathrm{H}$, Kosunen $\mathrm{E}$, Metsanoja $\mathrm{R}$, el al. To resuscitate or not: a dilemma in terminal cancer care. Resuscitation 2001, 49:289-297.

11. Hinkka $H$, Kosunen $E$, Lammi EK, et al. Decision making in terminal care: a survey of finnish doctors' treatment decisions in end-of-life scenarios involving a terminal cancer and a terminal dementia patient. Palliat Med 2002, 16:195-204.

12. Hinkka H, Kosunen E, Metsanoja R, et al. Factors affecting physicians' decisions to forgo life-sustaining treatments in terminal care. J Med Ethics 2002, 28:109-114.

13. White B, Willmott L, Cartwright $C$, et al. Doctors' knowledge of the law on withholding and withdrawing life-sustaining medical treatment. Med J Aust 2014, 201:229-232.

14. Reichlin M. On the ethics of withholding and withdrawing medical treatment. Multidiscip Respir Med 2014, 9:39-6958-9-39.

15. Parks SM, Winter L. End of life decision-making for cancer patients. Prim Care 2009, 36:811-23.

16. Miccinesi G, Fischer S, Paci E, et al., EURELD consortium. Physicians' attitudes towards end-of-life decisions: a comparison between seven countries. Soc Sci Med 2005, 60:1961-1974.

17. Piili RP, Lehto JT, Luukkaala T, et al. Does special education in palliative medicine make a difference in end-of-life decision-making? BMC Palliat Care 2018, 17:94-018-0349-6.

18. Lofmark R, Nilstun T, Cartwright C, et al., EURELD Consortium. Physicians' experiences with end-of-life decision-making: survey in 6 European countries and Australia. BMC Med 2008, 6:4-7015-6-4.

19. Frost DW, Cook DJ, Heyland DK, et al. Patient and healthcare professional factors influencing endof-life decision-making during critical illness: a systematic review. Crit Care Med 2011, 39:1174-1189.

20. Garland A, Connors AF. Physicians' influence over decisions to forego life support. J Palliat Med 2007, 10:1298-1305.

21. Christakis NA, Asch DA. Physician characteristics associated with decisions to withdraw life support. Am 
J Public Health 1995, 85:367-372.

22. Piili RP, Metsanoja R, Hinkka H, et al. Changes in attitudes towards hastened death among Finnish physicians over the past sixteen years. BMC Med Ethics 2018, 19:40-018-0290-5.

23. World Health Organization. WHO Definition of Palliative Care, Geneva. 2002.

http://www.who.int/cancer/palliative/definition/en/ (accessed 5 Oct 2018)

24. Horn R. "I don't need my patients' opinion to withdraw treatment": patient preferences at the end-oflife and physician attitudes towards advance directives in England and France. Med Health Care Philos 2014, 17:425-435.

25. Escher M, Perneger TV, Rudaz S, et al. Impact of advance directives and a health care proxy on doctors' decisions: a randomized trial. J Pain Symptom Manage 2014, 47:1-11.

26. Chung GS, Yoon JD, Rasinski KA, et al. US Physicians' Opinions about Distinctions between Withdrawing and Withholding Life-Sustaining Treatment. J Relig Health 2016, 55:1596-1606.

27. Jox RJ, Schaider A, Marckmann G, et al. Medical futility at the end of life: the perspectives of intensive care and palliative care clinicians. J Med Ethics 2012, 38:540-545.

28. Kubler A, Adamik B, Lipinska-Gediga M, et al. End-of-life attitudes of intensive care physicians in Poland: of a national survey. Intensive Care Med 2011, 37:1290-1296.

29. Foo WT, Zheng Y, Kwee AK, et al. Factors considered in end-of-life care decision making by health care professionals. Am J Hosp Palliat Care 2013, 30:354-358.

30. Knaus WA, Wagner DP, Draper EA, et al. The APACHE III prognostic system. Risk prediction of hospital mortality for critically ill hospitalized adults. Chest 1991, 100:1619-1636.

31. Zimmerman JE, Kramer AA, McNair DS, et al. Acute Physiology and Chronic Health Evaluation (APACHE) IV: hospital mortality assessment for today's critically ill patients. Crit Care Med 2006, 34:1297-1310.

32. Martos-Benitez FD, Soto-Garcia A, Gutierrez-Noyola A. Clinical characteristics and outcomes of cancer patients requiring intensive care unit admission: a prospective study. J Cancer Res Clin Oncol 2018, 144:717-723.

33. The Finnish Medical Association. Physician's Ethics.

https://www.laakariliitto.fi/site/assets/files/1273/laakarin_etiikka_2013.pdf (accessed 6 Oct 2018). 
34. Bonetti M, Cirillo P, Musile Tanzi P, et al. An Analysis of the Number of Medical Malpractice Claims and Their Amounts. PLoS One 2016, 11:e0153362.

35. Marshall DC, Punglia RS, Fox D, et al. Medical Malpractice Claims in Radiation Oncology: A PopulationBased Study 1985-2012. Int J Radiat Oncol Biol Phys 2015, 93:241-250.

36. White BP, Willmott L, Cartwright $\mathrm{C}$, et al. Comparing doctors' legal compliance across three Australian states for decisions whether to withhold or withdraw life-sustaining medical treatment: does different law lead to different decisions? BMC Palliat Care 2017, 16:63-017-0249-1.

37. Kon AA. The shared decision-making continuum. JAMA 2010, 304:903-904.

\section{Tables legends}

Table 1. Characteristics of the participants.

Table 2. Numbers and proportions of physicians choosing a palliative care approach over active/intensive care for the terminally ill patient with a prostate cancer (scenario 1 ) and willing to give a voucher for hospice for the advanced breast cancer patient (scenario 2).

Table 3. Factors reported by the physicians to have influenced to their decisions concerning the care of the terminally ill prostate cancer patient.

Table 4. Different background factors and attitudes explaining the decision to choose active/intensive care $(n=482)$ over a palliative care approach $(n=610)$ concerning the prostate cancer patient with probably iatrogenic GI-bleeding and when he is waiting to meet his son or a minister (scenarios 1a-c) in forward logistic regression analysis. 
Table 5. Different background factors and attitudes explaining the willingness to give a voucher for hospice $(n=488)$ versus not $(n=610)$ for the patient with advanced breast cancer (scenario 2) in forward logistic regression analysis. 